\title{
Editorial announcement about Chinese translation
}

On behalf of the Editorial Board, we would like to express gratitude to Professor Ma Ying for the great amount of work done for the journal during the past years. Since 2006, she has been personally engaged in the translation into Chinese of all the abstracts of the papers published in Dairy Science \& Technology, which represents a huge amount of voluntary work. We would also want to thank Dr He Shenghua and $\mathrm{PhD}$ student $\mathrm{Li} \mathrm{Na}$, who have also been involved in the translating process in the last past year.

The translation into Chinese has certainly contributed to diffusing knowledge in Dairy Science among Chinese students. However, as English has become the universal scientific language within the international community, the usefulness of Chinese translation has been reconsidered. The time involved in this exercise has appeared to be another reason not to continue with these translations, as it delayed the publication process to some extent. Therefore, from this issue on, the journal will no longer contain Chinese abstract.

Anne Thierry

Editor-in-chief

Magalie Weber

Managing Editor 